\title{
Tracheal Collapse in Dogs
}

\section{Luiza Corteletti Torezani, Jeferson Gonçalves Pereira Junior, Beatriz Barbosa Kaiser, Marilia Bolsoni Teixeira, Marcela Priscila Keller Santiago, Jéssica Miranda Cota, Clairton Marcolongo Pereira*}

Faculty of Veterinary Medicine, Centro Universitário do Espírito Santo (UNESC), Colatina, Brazil

Email: *clairton.marcolongo@terra.com.br

How to cite this paper: Torezani, L.C., Pereira Jr., J.G., Kaiser, B.B., Teixeira, M.B., Santiago, M.P.K., Cota, J.M. and Pereira, C.M. (2021) Tracheal Collapse in Dogs. Open Access Library Journal, 8: e7257.

https://doi.org/10.4236/oalib.1107257

Received: February 20, 2021

Accepted: March 19, 2021

Published: March 22, 2021

Copyright (C) 2021 by author(s) and Open Access Library Inc.

This work is licensed under the Creative

Commons Attribution International

License (CC BY 4.0).

http://creativecommons.org/licenses/by/4.0/

\begin{abstract}
Tracheal collapse is characterized as dorsoventral flattening of tracheal rings, resulting from progressive cartilage degeneration, which can affect the cervical and intrathoracic trachea, being more common in middle-aged and small breeds. The aim of the present study was to review the pathophysiological, clinical aspects, and diagnostic methods of tracheal collapse in dogs. Tracheal collapse occurs due to the progressive degeneration of the cartilage of the trachea, the extraluminal pressure exceeds the capacity of sustaining the rings, leading to collapse and narrowing of the lumen, hindering the passage of air. Cough is the main clinical sign seen in animals with tracheal collapse. The correct evaluation and grading of the tracheal collapse will determine the best type of treatment. Most dogs respond well to clinical treatment. However, those who have unresponsive respiratory impairment can benefit from surgical intervention. Bronchoscopy is the best technique to assess the degree of involvement of the trachea, however, the animal needs to be sedated with general anesthesia. The tangential radiographic projection can be used for complementary assessment of the trachea, however, it must be performed with caution, since it can accentuate the clinical signs. The prognosis is directly related to the degree of involvement of the trachea and the presence or not of secondary pathologies.
\end{abstract}

\section{Subject Areas \\ Veterinary Medicine}

\section{Keywords}

Trachea, Collapse, X-Ray, Ethiology

\section{Introduction}

Tracheal collapse is defined as dorsoventral flattening of the tracheal rings, re- 
sulting from the progressive degeneration of cartilage, most frequently seen in middle-aged dogs, around 7 years of age and small breeds [1] [2]. The collapsed trachea portion may involve the thoracic or cervical area, with concomitant involvement of the areas being possible. The dyspnea observed during inspiration results in collapse of the cervical region and expiration in collapse of the thoracic region [3].

The contact of the luminal walls results in chronic inflammation, which in turn leads to a dry cough, perpetuating a vicious cycle of coughing and inflammation [2]. Coughing is the most common clinical sign and can be triggered by exercise, heat or arousal; usually with a chronic history, started weeks or months ago [4].

Radiographic examination is ideal for locating and grading airway collapse. Lateral radiographs of the chest, the cervical portion of the trachea, are recommended, comparing the phases of the respiratory cycle [1]. However, the radiographic examination can underestimate the presence of bronchial degeneration on chest radiographs, often having to be associated with other diagnostic methods for complete evaluation [2].

The aim of the present study was to review the pathophysiological, clinical aspects, and diagnostic methods of tracheal collapse in dogs.

\section{Pathophysiology and Clinical Signs}

The occurrence of tracheal collapse is not well specified and is considered multifactorial, with the clinical disease being caused by the weakening of the tracheal rings and secondary factors that favor the appearance of clinical signs [4]. Collapse can be classified into different degrees (Figure 1), according to the level of lumen involvement [1].
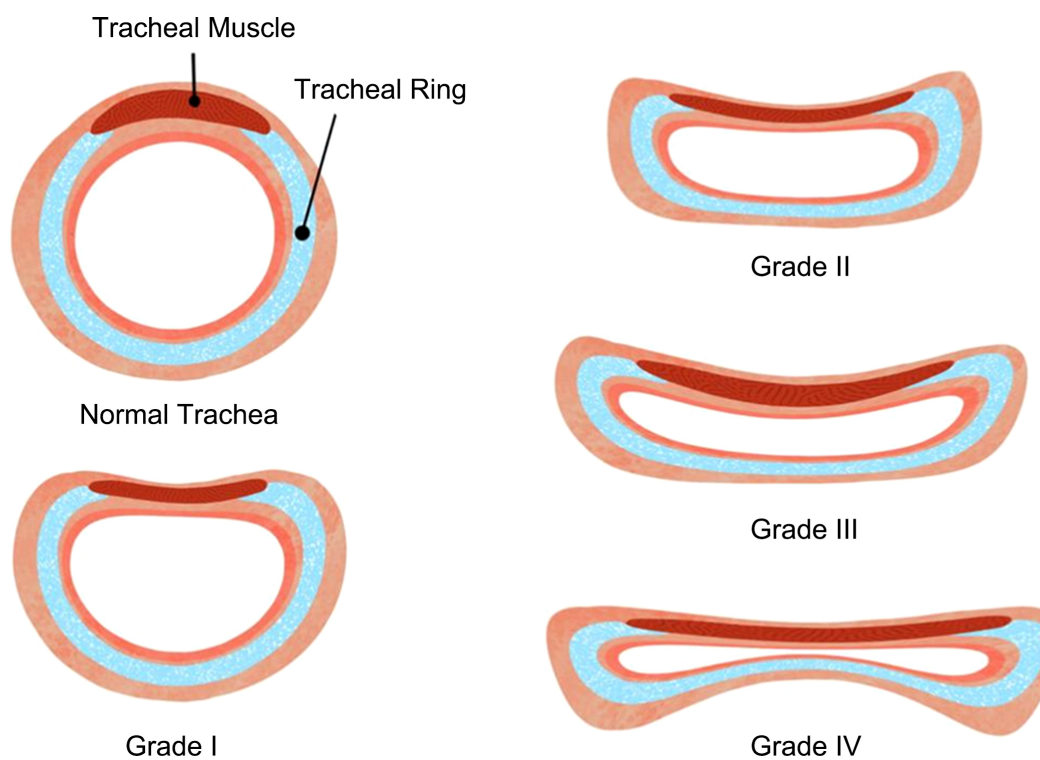

Figure 1. Different degrees of tracheal collapse according to the collapse of the tracheal lumen. Blue $=$ hyaline cartilage, Red $=$ tracheal muscle, Pink $=$ tracheal adventitia. 
The trachea is made up of cartilaginous rings that vary from individual to individual. The diameter of the tracheal lumen may vary according to breeds characteristics and the number of rings in its composition. Often, structural changes in the cartilage matrix cause softening of the cartilage rings, associated with reduced deposition of glycosaminoglycans and chondroitin sulfate, causing weakening and flattening of the tracheal rings [1] [4]. The rings are hypoplastic and fibrodystrophic and lose their ability to maintain their conformation. In an attempt to repair the lesion formed in the perichondium, it is replaced by a scar of fibrous connective tissue, which is the main cause that leads to deformity and loss of rigidity, and consequently incapacitating the lumen to maintain the diameter of the original light (Grades III and IV) [1].

In grades I and II, the muscle is pulled towards the lumen of the cervical portion of the trachea during inspiration and forced towards the intrathoracic trachea during expiration [5].

The pathology can also be linked to genetic factors or related to secondary causes, such as paresis and nutritional factors (obesity), allergens, respiratory diseases (chronic inflammation of the airways) and tracheal intubation [6].

Many dogs also present, during the evolution of the tracheal collapse, involvement of several segments of the upper airways [2]. Bronchomalacia is common in dogs with collapse of the trachea but can be found in dogs of any age and even in large breeds that do not have collapse of the trachea [1] [4]. Several animals remain asymptomatic until old age, but due to the degenerative disease of the tracheal cartilage and secondary factors, they can trigger the clinical picture of the tracheal collapse syndrome [7] [8].

Tracheal collapse is more common in small breeds such as Yorkshire Terriers, Poodle, Pugs, Pomeranian and Maltese. The main related clinical sign is the paroxysmal and noisy cough described as "goose squawking", associated or evidenced by infectious causes, excitation, tracheal compression or humid and hot climate [4] [6].

According to Clarke (2018), dogs with tracheal collapse have increased respiratory effort due to the weakening of the tracheal cartilage, which is unstable to the pressure generated during the passage of air, with greater inspiratory effort when the collapse is located in the cervical trachea or expiratory, when in the intrathoracic trachea.

Dyspnea is a common clinical sign, but variable in intensity: some animals do not show respiratory distress, while others have asphyxia, cyanosis and syncope and obese animals have more severe symptoms [6]. Some abnormal sounds can be seen, in addition to exercise intolerance and choking [2].

The symptomatic course of tracheal collapse perpetuates a vicious cycle of inflammation and cough, where the chronic inflammatory process causes metaplasia of the epithelium, impairing normal mucociliary cleaning and cough becomes the main means of tracheobronchial cleaning [4]. Hepatomegaly and liver disease can also be found, probably related to liver cell necrosis and passive liver 
congestion, secondary to chronic hypoxia [6].

Tracheal collapse should not be confused with tracheal stenosis, in which the latter occurs through congenital malformation or trauma. Stenosis occurs after injuries from penetrating or internal injuries, foreign bodies, internalized tubes or surgery, forming a scar that reduces the organ's light. It can be diagnosed by radiography or endoscopic examination [5].

\section{Diagnostic}

Tracheal collapse is suspected based on history, clinical signs and radiographic examinations; however, radiographic examination is essential to locate and classify the degree of collapse to monitor its clinical evolution and establish treatment [1]. Other techniques are also described as diagnostic, such as fluroscopy, ultrasound and endoscopy, which is the best technique for evaluating the bronchi and trachea [4].

Examinations, whether imaging or clinical, should be done with caution in patients with severe dyspnea, as they are at high risk of death. Most animals affected by the collapse have a history of chronic cough and respiratory distress. Palpation of the trachea, from the larynx to the entrance of the chest is important in the evaluation of the patient, and this analysis may be a trigger for the beginning of cough. It must be performed carefully, as the animals may present syncope, cyanosis and enter into a potentially fatal respiratory crisis. Auscultation may indicate strict sounds due to reduced tracheal light. Crepitation can occur in patients with bronchomalacia or with accumulation of mucus in the airways associated with simultaneous bronchitis [1].

Radiographic examination is the most used technique, since it is low-cost, non-invasive and does not require patient sedation. Three radiographic projections, including the cervical, thoracic and larynx portions, are ideal for all patients with suspected bronchotracheal collapse, also making it possible to assess the lung fields for concomitant respiratory diseases [2] [4]. The lateral projections of the neck and thorax give a diagnosis of approximately $60 \%$ of the cases of dogs with severe tracheal collapse (Figure 2). Traditional radiography can underestimate the clinical picture and lead to incorrect diagnoses [1]. Compressive radiography is widely used, but it has several limitations, due to the subjectivity of measuring external pressure and its interpretation, it can significantly interfere with the exam result [9].

It is possible to perform a complementary radiographic projection, with the dog positioned in sternal decubitus and with dorsal extension of the head and neck, with the incidence of the tangential x-ray beam at the entrance of the chest (Figure 3). This projection is of great importance for the diagnosis of tracheal collapse, however, greater attention should be paid, since this position can accentuate clinical signs [10] [11].

In dogs, the procedure that correlates the diameter of the trachea at the time of the thoracic entry and the diameter of the thoracic entry suggested by Harvey 


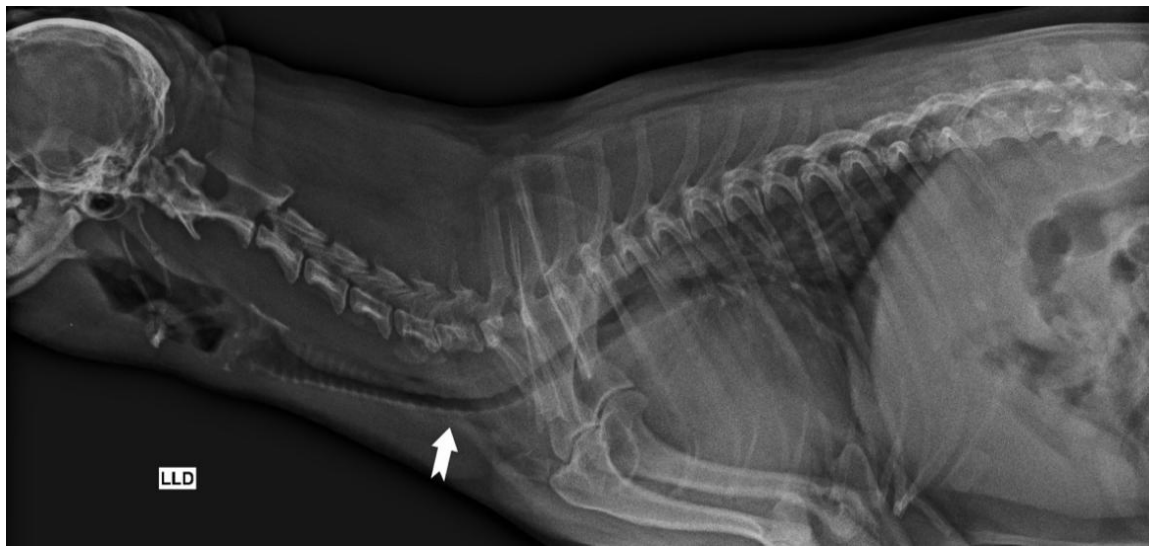

Figure 2. Conventional radiographic image of the cervicothoracic region via a lateral right-facing screening of a dog with tracheal closure (arrow).
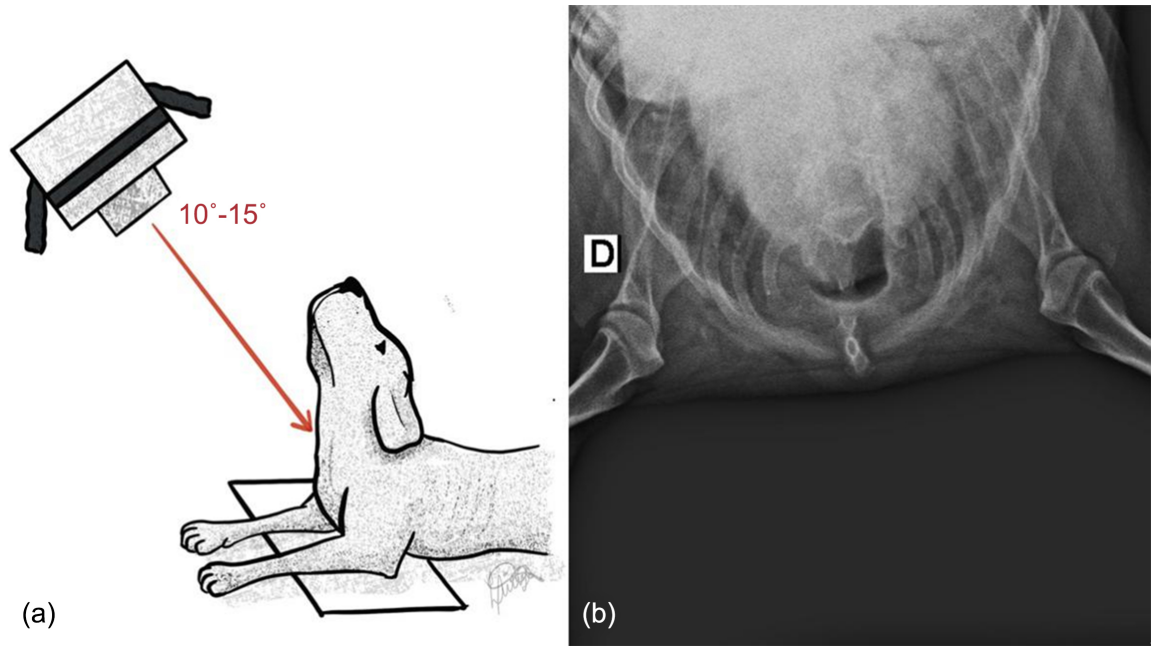

Figure 3. The craniocaudal tangential view of the thoracic inlet (a) can be used to show the tracheal lumen in cross section in order to appreciate its shape and extent of collapse (b).

and Fink (1982), is usually applied [12] [13] [14]. The thoracic entry was chosen as an anatomical reference because it remains on the same plane of the trachea, preventing magnification errors, such as those performed in the comparison procedure with the thickness of the third rib, where the furthest from the film is magnified in relation to the closest to him [14].

Bronchoscopy is the best technique for evaluation, as it allows visualizing the trachea and lower airways, but requires general anesthesia to be performed, since the bronchi cannot be accessed during normal breathing [1]. Bronchoscopy facilitates the graduation of tracheal collapse, according to the loss of the tracheal lumen (I: loss of $25 \%$ of the lumen, II: loss of $50 \%$, III: loss of $75 \%$ and IV loss greater than $75 \%$ ), but they do not always correspond with the severity of clinical signs [7]. It should preferably be performed with flexible endoscopes.

Tracheoscopy should be performed quickly, assessing the color, luminal diameter, position, vascularization and movement of the tracheal dorsal mem- 
brane, with tracheal collapse at the bronchial level being observed, which is difficult to observe on conventional radiography. Some pre-anesthetic mediations suppress the cough reflex and facilitate the examination, such as butorphanol $(0.22 \mathrm{mg} / \mathrm{kg})$ or oxymorphone $(0.05$ to $0.1 \mathrm{mg} / \mathrm{kg})$. The degree of laxity, flattening of the trachea and bronchi and the annular shape are easily observed in this exam [5].

\section{Treatment}

The clinical approach is more appropriate for animals that have less than $50 \%$ of collapsed tracheal lumen and mild clinical signs, commonly associated with grades I and II of collapse classification, which will lead to a better response to treatment. Many dogs respond well to medical therapy, with surgery interventions reserved for those refractory to treatment or with severe clinical signs such as cyanosis, exercise intolerance or dyspnoea. Identifying the underlying cause and interrupting the pathological process is a fundamental factor [2]. Changes in the environment must be instituted in order to keep the animal in an environment with minimal humidity. Recognizing and reducing specific environmental factors that increase barking, anxiety and arousal can help to decrease the coughing stimulus, in addition to excluding stimulation collars and direct compression of the trachea. Medications such as antitussives, antibiotics, bronchodilators and corticosteroids can help treat the underlying cause [1].

When infection and inflammation have been properly treated, antitussives are recommended to reduce chronic irritation and control cough. These suppressants are often the only therapy used for cough associated with collapse of the cervical trachea. The most used medications in this classification are hydrocodone. Antibiotics can play an important role in treating secondary infections that act as an inciting cause for airway irritation. Doxycycline can be considered by means of culture and antibiogram results, as well as for anti-inflammatory effect [1] [4].

Glucocorticoids are often used in the short term to reduce edema of the larynx, trachea and bronchi, unless a concomitant infection is suspected, and can be used in the initial treatment with prednisone. Steroid therapy should be meticulously evaluated for its benefit. They should be used strategically, in short periods of time and at the lowest possible doses for clinical signs control, as adverse effects can worsen long-term clinical signs [1].

Bronchodilators are suitable in all stages of treatment, with theophylline and aminophylline being the most used drugs. Bronchodilators have no effect on the larger airways that are visible during endoscopy and are not indicated for treatment of cervical tracheal collapse. They can play an important role when lower airway collapse is suspected or bronchomalacia is confirmed in bronchoscopic evaluation, although the response is variable. In cases where there is excessive production of mucus, it is recommended to use mucolytics, such as atropine, acetylcysteine and nebulization with saline solution [8] [15]. 
Surgical treatment is suitable for cases in which there is no response to the clinical treatment applied and for animals that have moderate to severe clinical signs with a $50 \%$ or more decrease in the tracheal lumen. The techniques described in the literature include folding the dorsal membrane, intraluminal devices and insertion of tracheal ring prostheses [1].

Dorsal membrane pleating is used in patients with rigid and normal rings and a loose and stretched tracheal membrane (grades I and II) and prevents the loose dorsal membrane from decreasing the tracheal lumen. The implantation of extralumial tracheal rings is indicated in the collapse of the cervical trachea and laryngeal paralysis is listed as a possible complication. When these devices are sutured to the cartilage rings, the airway wall is expanded. If intrathoracic tracheal collapse is diagnosed and cannot be treated clinically, placement of an intraluminal stent can be considered, with bacterial tracheitis, stent migration, stent deformation, prosthesis fracture, tracheal perforation during tissue placement and development obstructive granulation the most recurrent complications. The placement of intraluminal stents is indicated in cases where urgent airway clearance is required, in inoperable patients, or at high surgical risk [15].

\section{Prognosis}

The prognosis is proportional to the level of severity of the collapse and, mainly, the presence or absence of secondary pathologies. It is favorable for patients under drug treatment with controlled conditions and with evaluations during acute episodes of signs and reserved in cases that are not responsive to appropriate clinical treatment and that present exacerbated clinical signs [1].

\section{Conclusion}

Cough is the main clinical sign seen in animals with tracheal collapse. The correct evaluation and grading of the tracheal collapse will determine the best type of treatment. Most dogs respond well to clinical treatment. However, those who have unresponsive respiratory impairment can benefit from surgical intervention. Bronchoscopy is the best technique to assess the degree of involvement of the trachea, however, the animal needs to be sedated with general anesthesia. The tangential radiographic projection can be used for complementary assessment of the trachea, however, it must be performed with caution, since it can accentuate the clinical signs. The prognosis is directly related to the degree of involvement of the trachea and the presence or not of secondary pathologies.

\section{Acknowledgements}

This work was supported by Fundação de Amparo à Pesquisa e Inovação do Espírito Santo (FAPES), and was financed in part by the Coordenação de Aperfeiçoamento de Pessoal de Nível Superior (CAPES), Brasil-Finance code 001.

We thank the technician Bruno Coimbra for his assistance with radiographic images. 


\section{Conflicts of Interest}

All authors declared that they do not have any conflict of interest to disclose.

\section{References}

[1] Maggiore, A.D. (2014) Tracheal and Airway Collapse in Dogs. Veterinary Clinics of North America: Small Animal Practice, 44, 117-127. https://doi.org/10.1016/j.cvsm.2013.09.004

[2] Clarke, D.L. (2018) Interventional Radiology Management of Tracheal and Bronchial Collapse. Veterinary Clinics of North America: Small Animal Practice, 48, 765-779. https://doi.org/10.1016/j.cvsm.2018.05.010

[3] Ettinger, S.J., Kantrowitz, B. and Brayley K. (2004) Doenças da Traqueia. In: Ettinger, S.J. and Feldman, E.C., Eds., Tratado de Medicina Interna Veterinária, 5th Edition, Guanabara, Rio de Janeiro, 1096-1112.

[4] Tappin, S.W. (2016) Canine Tracheal Collapse. Journal of Small Animal Practice, 57, 9-17. https://doi.org/10.1111/jsap.12436

[5] Nelson, A.W. (2007) Afecções da traqueia e dos brônquios. In: Slatter, D., Ed., Manual de cirurgia de pequenos animais, 3th Edition, Editora Manole, São Paulo, 858-863.

[6] Fossum, T.W. (2008) Cirurgia do sistema respiratório superior. In: Fossum, T.W., Ed., Cirurgia de Pequenos Animais, $3^{\text {a }}$ ed, Roca, São Paulo, 817-866.

[7] Done, S.H., Clayton-Jones, D.G. and Price, E.K. (1970) Tracheal Collapse in the Dog: A Review of the Literature and Report of Two New Cases. Journal of Small Animal Practice, 11, 743-750. https://doi.org/10.1111/j.1748-5827.1970.tb05579.x

[8] Sun, F., Usón, J., Ezquerra, J., Crisóstomo, V., Luis, L. and Maynar, M. (2008) Endotracheal Stenting Therapy in Dogs with Tracheal Collapse. The Veterinary Journal, 175, 186-193. https://doi.org/10.1016/j.tvjl.2007.01.011

[9] Beltrán, K.G., Pascon, J.P.E. and Mistieri, M.L.A (2020) Radiographic Evaluation of Tracheal Collapse in Dogs by Compressive Technique. Arquivo Brasileiro de Medicina Veterinária e Zootecnia, 72, 799-806. https://doi.org/10.1590/1678-4162-11324

[10] Alexander, K. (2014) Laringe, Faringe e Traqueia. In: Thrall, D.E., Ed., Diagnóstico de radiologia veterinária, 6th Edition, Elsevier Saunders, Rio de Janeiro, 489-499.

[11] Coelho, M.R., Muzzi, R.A.P.L., Silva, A.C., Muzzi, L.A.L. and Figeuredo, V.C. (2014) Atualizações sobre tosse em cães. Revista Científica Eletrônica de Medicina Veterinária, 22, 1-20.

[12] Coyne, B.E. and Fingland, R.B. (1992) Hypoplasia of the Trachea in Dogs: 103 Cases (1974-1990). Journal of the American Veterinary Medical Association, 201, 768-772.

[13] Meola, S.D. (2013) Brachycephalic Airway Syndrome. Topics in Companion Animal Medicine, 28, 91-96. https://doi.org/10.1053/j.tcam.2013.06.004

[14] Harvey, C.E. and Fink, E.A. (1982) Tracheal Diameter: Analysis of Radiographic Measurements in Brachycephalic and Nonbrachycephalic Dogs. Journal of the American Animal Hospital Association, 18, 570-576.

[15] Sessegolo, G.M. (2013) Endoprótese (stent) intraluminal autoexpansivo, Adaptada por traqueoscopia, em cães com colapso de traqueia. Tese de Mestrado em Medicina Veterinária-Universidade Federal do Rio Grande do Sul. 